\title{
Acoustic Parameters in Persian-Speaking Patients with Dysphonia
}

\section{Farhad Torabinenezhad ${ }^{1}$, Farzad Izadi², Abbas Pourshahbaz ${ }^{* 3}$, Mahmood Bijankhan ${ }^{4}$, Moharam Eslami ${ }^{5}$, Mohammad Rohani ${ }^{6}$, Mona Ebrahimipor ${ }^{7}$}

1. Assistant Professor, Department of Speech \& Language Pathology, School of Rehabilitation Sciences, Iran University of Medical Sciences, Tehran, Iran

2. Professor, Department of ENT, Hazrat Rasoul Medical Complex, Iran University of Medical Sciences, Tehran, Iran

3. Associate Professor, Department of Clinical Psychology, Social Welfare \& Rehabilitation Sciences University, Tehran, Iran

4. Professor, Department of Linguistics, University of Tehran, Tehran, Iran

5. Associate Professor, Department of Linguistics, University of Zanjan, Zanjan, Iran

6. Associate Professor, Department of Neurology, Hazrat Rasoul Medical Complex, Iran University of Medical Sciences, Tehran, Iran

7. Assistant Professor, Department of Speech Therapy, Social Welfare \& Rehabilitation Sciences University, Tehran, Iran

\section{Article Info}

Received: 2018/08/13

Accepted: 2018/09/30

Published Online: 2018/10/28

DOI: 10.30699/fdisj.1.3.8

\section{How to Cite This Article}

Torabinenezhad F., Izadi F., Pourshahbaz A., Bijankhan M., Eslami5 M., Rohani M., Ebrahimipor M. Acoustic Parameters in Persian-Speaking Patients with Dysphonia. Function and Disability Journal. 2018 (Autumn).Val 1. No: 4 Pages: 8-17.

Use your device to scan and read the article online

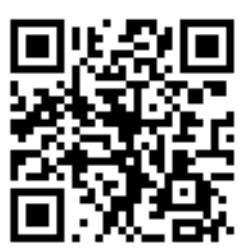

\section{ABSTRACT}

Background \& Objectives: Studying voice acoustic parameters in vowel production is a crucial component of every standard voice evaluation. Voice Analysis is non-invasive. Nowadays, computerized Voice Analysis is growing rapidly. Therefore, understanding acoustic parameters in healthy and unhealthy individuals is more significant than before. This research is a step toward boosting our knowledge about voice acoustic parameters. The main purpose of this research is to study acoustic characteristics in dysphonic and healthy Iranian individuals.

Methods: The current study was descriptive-analytic. Vowel Analysis was conducted through Praat software. Voices of 50 dysphonic patients and 50 healthy participants were evaluated. The acoustic parameters included average, standard deviation, and range of fundamental frequency, jitter, shimmer, the number and degree of voice breaks, and harmonic to noise ratio.

Results: In all studied acoustic characteristics, patients' mean scores were higher than controls' mean scores, except for harmonic to noise ratio which was higher in the healthy individuals. Although, the number of voice breaks in healthy male and female population was zero, it was 1.8 in male patients and 4.4 in female patients $(P<0.05)$.

jitter and shimmer in patients were dramatically higher $(P<0.05)$ than their amount in healthy controls; moreover, patients' fundamental frequency range (male: 54.6 \pm 59.0 , female: $78.6 \pm 68.4$ ) was extremely broader than individuals with normal voices (male: 9.7 \pm 4.1 , female: $16.2 \pm 7.3$ ).

Conclusion: It was clarified that there are considerably significant differences in some acoustic features. These differences may be used as a foundation for diagnosis and intervention in dysphonic patients. This study illustrated that Acoustic Analysis can differentiate healthy individuals from patients. Hence, it can be used as a noninvasive, fast and accurate method.

Keywords: Voice acoustic, Fundamental frequency, Voice break, Perturbation. 


\section{Introduction}

Voice is one of the main communication tools (Nicolosi, Harryman, Kresheck, 2004). All languages use voice extensively and systematically. Voice is the product of complex multi-dimensional system, and is a combination of anatomical, physiological, and neurological systems with a complicated coordination (Zojaji, Mirzadeh, Nourian, Sadeghi, 2007). Voice is a unique capacity which makes the speech audible and also expresses our emotions and thought. Every person has an individualized voice which not only reflects physical status of larynx (Chen et al., 2010), but it can also be affected by overall health (Saloni, Sharma, Gupta, 2013). Acoustic properties play an important role in optimal and effective communication. These parameters i.e. fundamental frequency (F0), jitter, shimmer, and harmonics-to-noise ratio (HNR) can provide some of the crucial properties of vocal health (Zojaji, Mirzadeh, Nourian, Sadeghi, 2007; Eadie, Stepp, 2013).

In a typical voice, vocalization can be continued with ease for a period of time. However, it is not the same in some voice disorders. There may be some interruptions in abnormal vocalization which can be examined by Praat software through the following methods: (I) the number of voice breaks i.e. the number of intervals between continuous pulses; and (II) the amount of voice break defined as the total duration of voice breaks in the period of vocalization.

F0 directly indicates the vocal cords vibration which is evaluated through vowel or speech production (Zraick, Wendel, Smith-Olinde, 2005). In fact, measuring the F0 during vowel production is more prevalent and convenient. Vowel /æ/ which is an open vowel is often chosen to evaluate voice. It is also expected that women have a higher F0 than men. Three factors determine the fundamental frequency: length, volume and tension of the vocal folds (Dehqan, Ansari, Bakhtiar, 2010). Length and volume of the vocal cords are different in two sexes, but tension can affect the frequency independently from the sex. As a case in point, a young man with Falsetto, a functional disorder, produce a high pitch voice due to the vibration of the middle of the vocal cords while there is no problem with length and volume of the vocal cords. In brief, F0 is a crucial factor which should be included in all voice assessments. However, its diagnostic value is another issue. It may be inappropriate to differentially diagnose a voice disorder just based on the F0. The following points should be taken into consideration in F0 assessing: It should be static during the production, but there are actually some fluctuations which make the vibration relatively static. This phenomenon can be investigated through the range of F0 variations and pitch standard deviation ${ }^{1}$. These measures are expected to be slight in a normal voice (Deliyski, Dimitar, 2001); otherwise, it is diagnosed as abnormal.

The perturbation of vocal cord vibration is also quantifiable by means of two factors: jitter and shimmer. Jitter manifests perturbation between consecutive signals of the larynx, and shimmer measures the perturbations in the signal amplitude of the larynx (Zojaji, Mirzadeh, Nourian, Sadeghi, 2007). One of the most appropriate (practical) factors in voice evaluation is harmonicity or HNR indicating the degree of acoustic periodicity. If $99 \%$ of the energy of the signal is in the periodic part, and $1 \%$ is noise, the HNR is $20 \mathrm{~dB}^{2}$. A HNR of $0 \mathrm{~dB}$ means that there is equal energy in the harmonics and in the noise (Boersma, Weenink, 2006). This index can be used to survey the quality of voice. A normal human is able to continuously produce vowel /æ/ with a HNR of about $20 \mathrm{~dB}$. Higher frequencies may have higher HNR. In contrast, vocal hoarseness reduces this amount.

Clinicians believe that considering multiple parameters in assessment is more reliable and suitable than clinical judgment based on one parameter, such as F0 or jitter or shimmer (Schindler et al., 2009; Wolfe, Martin, 1997). Voice disorders occur in \%3 of adults (Boone, McFarlane, Von Berg, Zraick, 2005). Voice

\footnotetext{
${ }^{1}$.Praat software measures pitch standard deviation in each participant individually and reports it in voice analysis under the same term.

${ }^{2}$.HNR is expressed in decibel.
} 
scientists, speech \& language pathologists, and therapists devote most of their energy, talent, and time to diagnose and evaluate the severity of voice disorder. They do this by various perceptual, acoustic or physiological tools (Dibazar, Berger,\& Narayanan, 2006). In other words, voice properties can be examined instrumentally or non-instrumentally. Instrumental evaluation is done through a variety of software (Finger, Cielo, Schwarz, 2009; Naufel, Grillo, Grechi, 2006). Examiner's errors do not occur in instrumental analysis and this is the priority of this kind of evaluation. The results of acoustic evaluation can easily be compared with normal population and leads to a more precise diagnosis. Nowadays, instrumental evaluation is worldwide, because of the accessibility of computers and electronic devices (Zojaji, Mirzadeh, Nourian, Sadeghi, 2007).

For several decades these properties have been frequently examined in various languages, especially English language. However, there are only few studies on Persian speakers' voice characteristics (Zojaji, Mirzadeh, Nourian, Sadeghi, 2007; Dehqan, Ansari, Bakhtiar, 2010; Aghadoost, Amiri-Shavaki, Moradi, Jalai, 2013), and there are actually no studies on the range of fundamental frequency, pitch standard deviation, number and degree of voice breaks in Persian language speakers. Furthermore, some studies measured acoustic features in Persian speakers and used it to evaluate the efficiency of their intervention, but unfortunately there is no published data on that (Safari, Amiri-Shavaki, Ghorbani, Izadi, 2009).

In the present research, less studied factors were taken into careful consideration and the measurement conciseness was improved by more advanced equipment such as external sound card, condenser microphone, and use of "TextGrid" (Pépiot, 2014) in order to have a more reliable results.

The main purpose of this study was to investigate the acoustic properties in dysphonic patients and their differences with normal Iranian population. Clinical intervention requires precise pre and post evaluation in order to document the patients' improvement (Zojaji, Mirzadeh, Nourian, Sadeghi,
2007) and decide about how to continue the treatment. For these reasons, clinicians and researchers need to be knowledgeable about the vocal characteristics of their native language (Naufel, Grillo, Grechi, 2006; Wang, \& Huang, 2004). In other words, the second aim of this research was to meet some parts of this requirement.

\section{Materials and Methods}

\section{Participants}

100 individuals participated in this study; half of them were healthy ( 34 men and 16 women) and the others were dysphonic (33 men and 17 women). The sample size was calculated based on the following formula: $\mathrm{n}=16 \mathrm{~s} 2 / \mathrm{d} 2$ (Streiner, 2013).

The inclusion criteria for the case group included: Speaking Persian language as the maternal one with the standard accent, no history of neurologic and systemic diseases, and avoidance of smoking and alcohol. The patients were selected from ENT clinic of Hazrat Rasoul Medical Complex, Iran University of Medical Sciences (IUMS). Their voice disorder and its type were confirmed by a fellowship of laryngology. Furthermore, their voice problem was ascertained by two speech and language pathologists (Naufel, Grillo, Grechi, 2006) who were expert in voice disorders. None of the patients were aphonic. Their mean age was $44.60 \pm 14.04$ years. The distribution of the type of voice disorder can be seen in Table 1. Normal individuals were chosen from the employees of a company.

The inclusion criteria for the control group were similar to the other group. In addition, they should not have a history of neck and larynx surgery, or taking medication at the research period (Finger, Cielo, Schwarz, 2009). Their mean age was $40.66 \pm 11.53$ years. This study was accomplished from May to September 2014. 
Table 1. The Distribution of the Type of Voice Disorder

\begin{tabular}{|ccc|}
\hline Etiology & Frequency & Percent \\
\hline Functional & 13 & 26.0 \\
\hline Neurogenic & 24 & 48.0 \\
\hline Organic & 13 & 26.0 \\
\hline Total & 50 & 100.0 \\
\hline
\end{tabular}

\section{Speech Task and Voice Recording}

The headset microphone (Unidirectional, BBSMU-435, Hong Kong) was placed 10-15 cm from the speaker's mouth and at a $45^{\circ}$ angle from the speaker's mouth. The microphone was previously calibrated by the sound level meter (Awan, Giovinco, \& Owens, 2012).

Every examinee produced vowel /æ/ continuously for 5 seconds (Naufel, Grillo, Grechi, 2006; Awan,\& Roy, 2005). The voice was recorded (Laptop Samsung - model: 300E, china) by JetAudio application with "wav" format and sample rate of $44100 \mathrm{KHz}$ (Dirk, \& Braun, 2011), through external sound card (Mackie ONRX Black Jack-USB, USA) (Aghadoost, AmiriShavaki, Moradi, Jalai, 2013; Dehqan,\& Scherer, 2013). Then every voice was saved separately. All voices were recorded at 9-13 o'clock (Toran, \& Lal, 2009) in a quiet room (Dejonckere et al., 2001).

\section{Voice Analysis}

Recorded voices were opened in Praat (Version 5.1.17) (Boersma,\& Weenink, 2009) software (Finger, Cielo, Schwarz, 2009; Sonu, 2012), and a "TextGrid" was made for each participant. In this section, the median 3 seconds of vowel was selected (Zojaji, Mirzadeh, Nourian, Sadeghi, 2007; Felippe, Grillo, Grechi, 2006) and its "TextGrid" was saved. Then, the script (Pépiot, 2014) section was activated in Praat software. And all voices were analyzed with suitable script.

All data were categorized and analyzed statistically by SPSS17. The information included average, standard deviation, and range of fundamental frequency, jitter, shimmer, the number and degree of voice breaks, and HNR. These parameters were considered as acoustic characteristics (Dirk, \& Braun, 2011; Sonu, 2012; Felippe, Grillo,\& Grechi, 2006).

\section{Statistical Analysis}

The statistical analysis (K-Stest) revealed that the only variable which followed the normal distribution was the HNR. Therefore, independent $t$-test and Mann-Whitney tests were used to identify the mean differences in HNR and other variables respectively.

\section{Ethical Considerations}

In this study, the participants received information concerning the study, and all participants signed the informed consent before participation. They were assured that their information would remain confidential. The researchers observed all ethical issues in accordance with the Helsinki Convention.

\section{Results}

The patients' mean values were higher than normal population in all eight acoustic features except the HNR which was higher in the second group. The differences in some of the acoustic features were enormous, like the pitch standard deviation in the patients, which was 8 times higher than the controls' scores. On the other hand, there were some features which did not differ dramatically between two groups (Table 2).

The findings of this study showed that there is no significant difference for F0 between the healthy and the dysphonic subjects. The results indicated that the mean of pitch standard deviation were 2.2 in normal women and 18.3 in female patients. Likewise, it was 1.7 in normal men and 16.0 in male patients. It is obvious that the difference between two case and con- 
trol groups were significant $(P<0.05)$. Similarly, patients had a significantly broader mean $\mathrm{F} 0$ range than normal subjects.

Based on our findings, the amount of jitter differed significantly $(P<0.05)$ between case and control groups. Likewise, patients' shimmers were remark- ably $(P<0.05)$ higher than shimmer in the control group. In the present study, there was a significant difference $(P<0.05)$ in HNR between two groups.

Similarly, the number and the amount of voice breaks, differed significantly in the case and control groups $(P<0.05)$.

Table 2. Mean of Acoustic Characteristics in Normal \& Patients Groups

\begin{tabular}{|c|c|c|c|c|c|}
\hline \multirow{2}{*}{ Sex } & \multirow{2}{*}{$\begin{array}{c}\text { Acoustical } \\
\text { Characteristics }\end{array}$} & \multicolumn{2}{|c|}{ Health Group } & \multicolumn{2}{|c|}{ Dysphonic Group } \\
\hline & & Mean & St. Dev. & Mean & St. Dev. \\
\hline \multirow{8}{*}{ 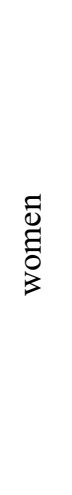 } & F0 Ave & 200.4 & 19.2 & 209.5 & 35.1 \\
\hline & Pitch Std & 2.2 & 0.9 & 18.3 & 21.6 \\
\hline & F0 range & 16.2 & 7.3 & 78.6 & 68.4 \\
\hline & Jitter & 0.004 & 0.001 & 0.018 & 0.025 \\
\hline & Shimmer & 0.036 & 0.014 & 0.074 & 0.049 \\
\hline & HNR & 20.7 & 2.8 & 15.1 & 8.4 \\
\hline & No. VB & 0 & 0 & 4.4 & 6.7 \\
\hline & Dg. VB & 0 & 0 & 0.2 & 0.2 \\
\hline \multirow{8}{*}{$\begin{array}{l}\bar{\Xi} \\
\stackrel{\Xi}{ }\end{array}$} & F0 Ave & 125.6 & 15.9 & 136.1 & 28.3 \\
\hline & Pitch Std & 1.7 & 0.7 & 16.0 & 22.7 \\
\hline & F0 range & 9.7 & 4.1 & 54.6 & 59.0 \\
\hline & Jitter & 0.003 & 0.001 & 0.019 & 0.025 \\
\hline & Shimmer & 0.030 & 0.017 & 0.097 & 0.066 \\
\hline & HNR & 20.2 & 4.2 & 12.0 & 7.0 \\
\hline & No. VB & 0 & 0 & 1.8 & 3.0 \\
\hline & Dg. VB & 0 & 0 & 0.1 & 0.2 \\
\hline
\end{tabular}

Abbreviations: F0= Fundamental frequency, F0 Ave= Fundamental frequency Average, Pitch Std= Pitch Standard deviation, $\mathrm{F} 0$ range $=$ Fundamental frequency range, $\mathrm{HNR}=$ Harmonics to noise ratio, No. VB= Number of Voice

Breaks, Dg. VB= Degree of Voice Breaks, St. Dev.= Standard deviation.

\section{Discussion}

The mean of F0 in normal male and female were 125.6 Hz and $200.4 \mathrm{~Hz}$, respectively. This variance is resulted from the anatomical differences. Besides, the patients' F0s (male: 136.1 and female: 209.5) were slightly but insignificantly higher than the normal population. This finding is consistent with Lowell and et al. (2012) stating that there is no significant difference in F0 between patient (MTD) and control groups. Dehghan et. al. (2010) reported a significant difference between typical men and women's mean fundamental frequencies $(126.1 \mathrm{~Hz}$ and $214.6 \mathrm{~Hz}$ respectively). Similarly, Wang \& Huang (2004) provided evidence on this difference. There was also a significant difference between sexes in this study. Although there is some minor diversity between these findings, but it is probably resulted from individual differences and/or the dissimilarity in analytic systems. In contrast, there is no consensus on the F0 difference between healthy and unhealthy voices. In order to reach a better judgment for F0, we need to take advantage of the data from the $\mathrm{F} 0$ range and pitch standard deviation. As mentioned earlier, our partici- 
pants were asked to produce a vowel continuously and constantly; therefore, the F0 range was expected to be minor (Little, 2009). Baken \& Orlikoff (2000) suggested $10 \mathrm{~Hz}$ of F0 variation in normal men and low pitch voice, and about $30 \mathrm{~Hz}$ of $\mathrm{F} 0$ variations in female voice. This range is one octave higher in healthy women. Although the range of F0 variation is so limited in the normal population, it was so broad among our patients. Previously, there had been no data on the F0 range in Persian speakers. Little (2009) verified the difference in F0 range between healthy individuals and patients with Parkinson's disease. There are also more investigations confirming this difference (Goberman,\& Blomgren, 2008; Stepp, Hillman,\& Heaton, 2010). The other important factor is the pitch standard deviation. The lower the pitch standard variation is, the less variation in F0 during a speech would be expected. The relationship between the speed of recovery from spasmodic dysphonia and the pitch standard deviation during speech have been known for many years (Eadie, Stepp, 2013; Goberman,\& Blomgren, 2008 ). The difference between two groups in mean of pitch standard deviation was highly significant in this study, and from this point of view, this research was consistent with the previous ones.

As the preceding investigations illustrated, any organic, neurologic, or functional change in the larynx may alter voice and shaken its acoustic features. Consequently, the jitter and shimmer increase. They are obviously the indicator of interruption in frequency and intensity. In this survey, the amount of jitter and shimmer differs significantly between case and control groups, which is consistent with findings of Casado et al. (2001), Shao et al. (2010) and Olszewsk et al. (2011). In addition, Dehghan et al. (2010) investigated jitter and shimmer in normal Persian speakers. Their findings are slightly different from our research which is probably due to using different software packages (Batalla et al., 2014). They used Dr. Speech software which is designed for clinical work, and its accuracy in determining time period is less than Praat. Nonetheless, these two surveys are similar in their findings on insignificant jitter and shimmer dif- ferences in males and females (Awan, Giovinco,\& Owens, 2012).

There was a marked difference in HNR between case and control groups. It is worth mentioning that the mean of HNR in female patients was higher than this ratio in male patients, which is likely because of their higher F0. As mentioned earlier, HNR goes up with higher frequency. Dehghan and Scherer (2013) examined teachers' voices and similar to our study, concluded that the HNR in female teachers is notably higher than HNR in the control group. However, despite of our findings, they found no difference in HNR in the male population.

The vowel can be easily produced continuously with no breaks in normal people and in normal situations. In other words, voice break in the normal population is zero (Di Nicola, Fiorella, Spinelli, \& Fiorella, 2006). Hence the observation of "voice break" can be an appropriate indicator of voice disorder. The amount and number of voice breaks in our normal group were zero, unlike the patient group who obviously had voice breaks. Some researchers believe that voice breaks are one of the main characteristics of spasmodic dysphonia (Sebastian, Gowri, 2014; Dejonckere, Manfredi, 2011 ) and others recognize it as a diagnostic strategy for voice disorders (Dejonckere et al., 2001; Cannito, Buder, Chorna, Dressler, 2012). Consistent with our results, Nicola et al. (2006) illustrated that voice break in patients were 27 , while it was zero in healthy voice.

\section{Conclusion}

In this study, some acoustic parameters such as range of fundamental frequency, pitch standard deviation, number and degree of voice breaks were investigated in Persian language speakers for the first time and their value was determined in healthy and dysphonic individuals. This study revealed that acoustic features in dysphonic patients are incompatible with normal voice characteristics, especially in jitter, shimmer, HNR, pitch standard deviation, and range of fundamental frequency. Moreover, voice break can be an indicator of voice problem. Also, this study illustrated that acoustic analysis can differentiate healthy indi- 
viduals from patients. Hence, it can be used as a noninvasive, fast and accurate method. Our data may be used as relative criteria in voice assessment and intervention processes in every session. Furthermore, this data provides a valuable profile of acoustic characteristics in Persian speakers.

\section{Acknowledgment}

We express our special thanks to Nahid Jalilevand

\section{References}

Aghadoost, O., Amiri-Shavaki, Y., Moradi, N., \& Jalai, S. (2013). A comparison of dysphonia severity index in female teachers with and without voice complaints in elementary schools of Tehran, Iran. Nurs Midwifery Stud, 1(3), 133-8.

Awan, S. N., \& Roy, N. (2005). Acoustic prediction of voice type in women with functional dysphonia. Journal of Voice, 19(2), 268-282.

Awan, S. N., Giovinco, A., \& Owens, J. (2012). Effects of vocal intensity and vowel type on cepstral analysis of voice. Journal of voice, 26(5), 670-e15.

Baken, R. J., \& Orlikoff, R. F. (2000). Clinical measurement of speech and voice. Cengage Learning.

Batalla, F. N., Márquez, R. G., González, M. B. P., Laborda, I. G., Fernández, M. F., \& Galán, M. M. (2014). Acoustic Voice Analysis Using the Praat programme: Comparative Study With the Dr. Speech Programme. Acta Otorrinolaringologica (English Edition), 65(3), 170-176.

Boersma, P., \& Weenink, D. (2006). Praat manual. Amsterdam: University of Amsterdam, Phonetic Sciences Department.

Boersma, P., \& Weenink, D. (2009). Praat : doing phonetics by computer (Version 5.1. 17)[Computer program]. Retrieved September 1, 2009 (Computer program).

Boone, D. R., McFarlane, S. C., Von Berg, S. L., \& Zraick, R. I. (2005). The voice and voice therapy.

Cannito, M. P., Buder, E. H., Chorna, L. B., \& Dressler, R. (2012). Acoustic measures of phonation during connected speech in adductor spasmodic dysphonia. Otolaryngol S1, 3, 2.

Casado, J. M., Adrián, J. T., Conde, M. J., Piédrola, D.
(Head of Speech \& Language Pathology Department), \& Hessamodin Emamdjome as audiologist who helped us a lot in finishing this project.

This research was supported by grants provided by Department of Speech \& Language Pathology, affiliated to Iran University of Medical Sciences.

\section{Conflict of Interest Statement}

Authors declared no conflict of interest.

M., Povedano, V. R., Muñoz, E. G., ... \& Jurado, A. R. (2001). Objective study of the voice in a normal population and in dysphonia caused by nodules and vocal polyps. Acta otorrinolaringologica espanola, 52(6), 476-482.

Chen, S. H., Chiang, S. C., Chung, Y. M., Hsiao, L. C., \& Hsiao, T. Y. (2010). Risk factors and effects of voice problems for teachers. Journal of Voice, 24(2), 183-192.

Dehqan, A., Ansari, H., \& Bakhtiar, M. (2010). Objective voice analysis of Iranian speakers with normal voices. Journal of Voice, 24(2), 161-167.

Dehqan, A., \& Scherer, R. C. (2013). Acoustic analysis of voice: Iranian teachers. Journal of Voice, 27(5), 655e17.

Dejonckere, P., \& Manfredi, C. (2011). Long-term follow-up of patients with spasmodic dysphonia repeatedly treated with botulinum toxin injections. International Journal of Phonosurgery and Laryngology, 1(2), 57-60.

Dejonckere, P. H., Bradley, P., Clemente, P., Cornut, G., Crevier-Buchman, L., Friedrich, G., ... \& Woisard, V. (2001). A basic protocol for functional assessment of voice pathology, especially for investigating the efficacy of (phonosurgical) treatments and evaluating new assessment techniques. European Archives of Oto-rhino-laryngology, 258(2), 77-82.

Deliyski, S. A. X. D. (2001). Effects of aging on selected acoustic voice parameters: Preliminary normative data and educational implications. Educational Gerontology, 27(2), 159-168.

Di Nicola, V., Fiorella, M. L., Spinelli, D. A., \& Fiorella, R. (2006). Acoustic analysis of voice in patients treated by reconstruc-tive subtotal laryngectomy. Evaluation and critical review. Acta otorhinolaryngologica italica, 26(2), 59. 
15. Acoustic Parameters in Persian-Speaking Patients with Dysphonia

Dibazar, A. A., Berger, T. W., \& Narayanan, S. S. (2006). Pathological voice assessment. In Engineering in Medicine and Biol-ogy Society, 2006. EMBS'06. 28th Annual International Conference of the IEEE (1669-1673).

Dirk, L., \& Braun, A. (2011, August). Voice parameter changes in smokers during abstinence from cigarette smoking. In Proc. of International Congress of Phonetic Sciences (ICPhS XVII), HongKong, China, Hong Kong (pp. 17-21).

Eadie, T. L., \& Stepp, C. E. (2013). Acoustic correlate of vocal effort in spasmodic dysphonia. Annals of Otology, Rhinology \& Laryngology, 122(3), 169-176.

Felippe, A. C. N. D., Grillo, M. H. M. M., \& Grechi, T. H. (2006). Standardization of acoustic measures for normal voice patterns. revista Brasileira de Otorrinolaringologia, 72(5), 659-664.

Finger, L. S., Cielo, C. A., \& Schwarz, K. (2009). Acoustic vocal measures in women without voice complaints and with normal larynxes. Brazilian journal of otorhinolaryngology, 75(3), 432-440.

Goberman, A. M., \& Blomgren, M. (2008). Fundamental frequency change during offset and onset of voicing in individuals with Parkinson disease. Journal of Voice, 22(2), 178-191.

Little, M. A., McSharry, P. E., Hunter, E. J., Spielman, J., \& Ramig, L. O. (2009). Suitability of dysphonia measurements for telemonitoring of Parkinson's disease. IEEE transactions on biomedical engineering, 56(4), 1015-1022.

Lowell, S. Y., Kelley, R. T., Colton, R. H., Smith, P. B., \& Portnoy, J. E. (2012). Position of the hyoid and larynx in people with muscle tension dysphonia. The laryngoscope, 122(2), 370-377.

Naufel, dFA., Grillo, M., Grechi, T. (2006). Standardization of acoustic measures for normal voice patterns. Brazilian journal of otorhinolaryngology, 72(5), 659.

Nicolosi, L., Harryman, E., Kresheck, J. (2004). Terminology of communication disorders: speech-languagehearing: Lippincott Williams \& Wilkins.

Olszewski, A. E., Shen, L., \& Jiang, J. J. (2011). Objective methods of sample selection in acoustic analysis of voice. Annals of Otology, Rhinology \& Laryngology,
$120(3), 155-161$.

Pépiot, E. (2014, May). Male and female speech: a study of mean f0, f0 range, phonation type and speech rate in Parisian French and American English speakers. In Speech Prosody 7 (pp. 305-309).

Safari, M., Amirshuki, Y., Ghorbani, A., \& Izadi, F. (2009). The effect of speech therapy on laryngeal stroboscopic features of patients with vocal cord nodules. Iranian Journal of Otorhinolaryngology, 21(55), 11-16.

Saloni, R., Sharma, K., \& Gupta, A. K. (2014). Classification of High Blood Pressure Persons Vs Normal Blood Pressure Persons Using Voice Analysis. IJ Image, Graphics and Signal Processing, 47-52.

Schindler, A., Mozzanica, F., Vedrody, M., Maruzzi, P., \& Ottaviani, F. (2009). Correlation between the Voice Handicap Index and voice measurements in four groups of patients with dysphonia. Otolaryngology-Head and Neck Surgery, 141(6), 762-769.

Schötz, S. (2007). Acoustic analysis of adult speaker age. In Speaker Classification I (pp. 88-107). Springer, Berlin, Heidelberg.

Sebastian, S., Gowri, M. (2014). Differential diagnosis of adductor spasmodic dysphonia and muscle tension dysphonia using acoustic parameters. Otolaryngology online journal. 4(4), 22-7.

Shao, J., MacCallum, J. K., Zhang, Y., Sprecher, A., \& Jiang, J. J. (2010). Acoustic analysis of the tremulous voice: assessing the utility of the correlation dimension and perturbation parameters. Journal of communication disorders, 43(1), 35-44.

Sonu, RS. (2012). Disease Detection Using Analysis of Voice Parameters. TECHNIA - International Journal of Computing Sci-ence and Communication Technologies.

Stepp, C. E., Hillman, R. E., \& Heaton, J. T. (2010). The impact of vocal hyperfunction on relative fundamental frequency during voicing offset and onset. Journal of Speech, Language, and Hearing Research, 53(5), 12201226.

Streiner, D. L. (2013). A guide for the statistically perplexed: Selected readings for clinical researchers. University of Toronto Press.

Toran, K. C., \& Lal, B. K. (2009). Objective analysis 
of voice in normal young adults. Kathmandu University Medical Journal, 7(4), 374-377.

Wang, C. C., \& Huang, H. T. (2004). Voice acoustic analysis of normal Taiwanese adults. JOURNAL-CHINESE MEDICAL ASSOCIATION., 67(4), 179-184.

Wolfe, V., \& Martin, D. (1997). Acoustic correlates of dysphonia: type and severity. Journal of Communication Disorders, 30(5), 403-416.
Zojaji, R., Mirzadeh, M., Nourian, A., \& Sadeghi, H. (2007). Efficacy of voice laboratory in evaluation of treatment in dysphonic patients. Iranian Journal of Otorhinolaryngology, 19(49), 3-8.

ZZraick, R. I., Wendel, K., \& Smith-Olinde, L. (2005). The effect of speaking task on perceptual judgment of the severity of dysphonic voice. Journal of Voice, 19(4), 574581. 


$$
\text { مقالة يزوهشى }
$$

\section{شاخصهاى اكوستيكى در بيماران فارسى زبان مبتلا به كرفتتى صدا}

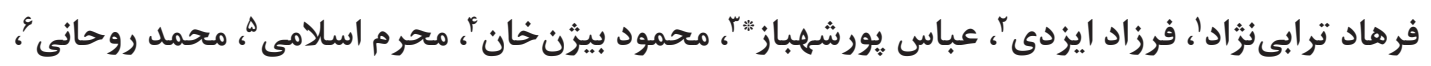 مونا ابر اهيمى يور مدود بيرن}

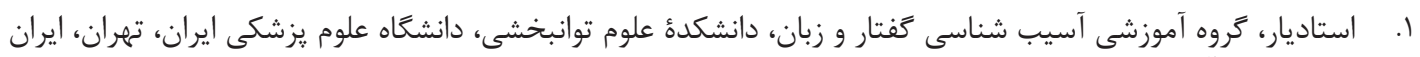

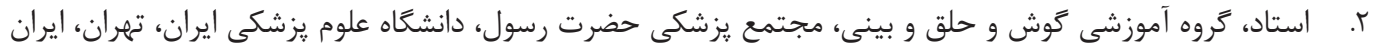

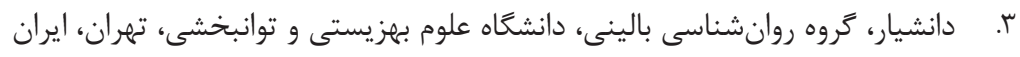

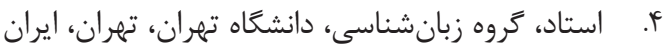

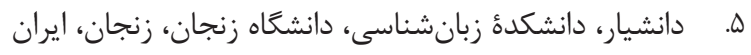

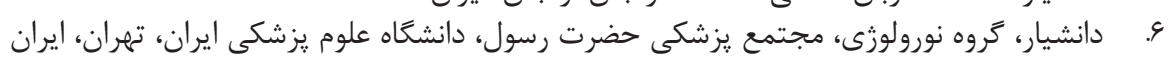

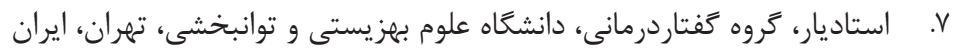

\begin{tabular}{|c|c|}
\hline קكيده & اطلاعات مقاله \\
\hline 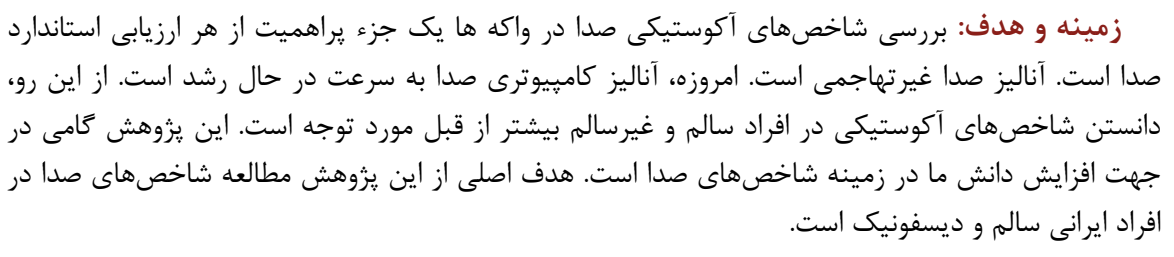 & 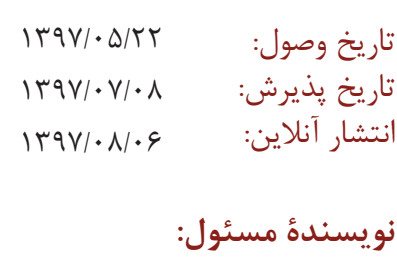 \\
\hline 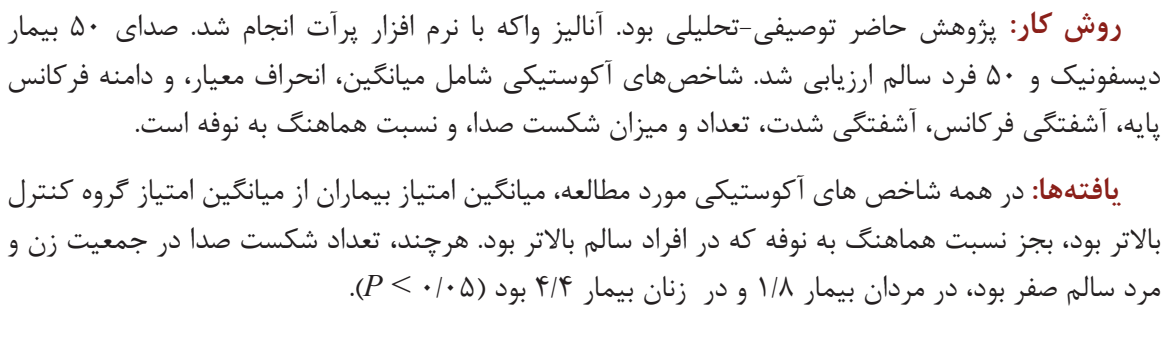 & 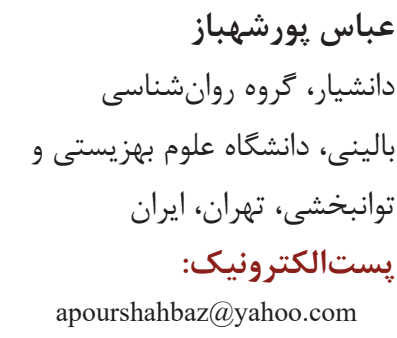 \\
\hline 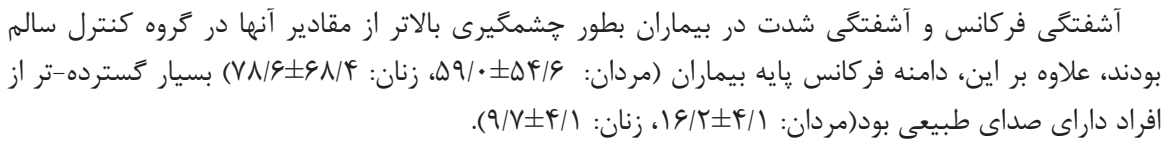 & 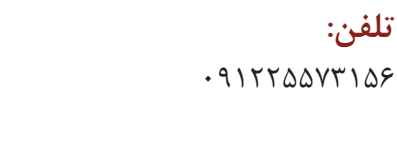 \\
\hline 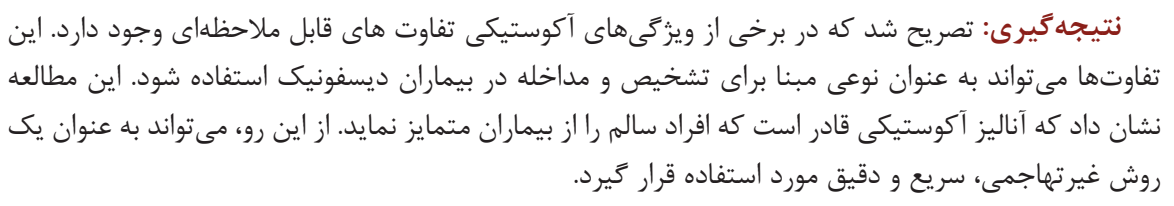 & \\
\hline هماهنَ به نوفه كليدى: آكوستيك صدا، فركانس بايه، شكست صدا، آشفتگى فر كانس، آشفتَى شدت، نسبت & \\
\hline
\end{tabular}

